\title{
POTENSI DAN TINGKAT PEMANFAATAN PERIKANAN PERAIRAN UMUM SEKITAR LAHAN PERSAWAHAN PASANG SURUT SUMATERA SELATAN
}

\begin{abstract}
Achmad S. Sarnita*)
ABSTRAK

Pengelolaan perikanan rawa banjiran (flood plains) di Indonesia masih belum banyak dilakukan, padahal luas lahan rawa banjiran cukup besar. Hal ini disebabkan terbatasnya pengetahuan di bidang pengelolaan perikanan rawa banjiran. Penelitian potensi dan tingkat pemanfaatan sumber daya perikanan di lahan rawa sulfat masam di Sumatera Selatan telah dilakukan pada bulan Juli 1998, September 1998, dan Januari 1999 dengan menggunakan metode survai. Tujuan penelitian adalah untuk mendapatkan data dan informasi mengenai sumber daya perikanan di lahan perairan sulfat masam tersebut dan di lahan pertanian pasang surutnya serta untuk mendapatkan informasi mengenai aspek budi daya ikan di lahan sulfat masam dalam rangka usaha pengembangan budi daya ikan di tipe lahan tersebut. Pengambilan sampel dan pengamatan lapang dilakukan dengan menggunakan metode sampling berstrata, di mana wilayah yang diteliti dibagi menjadi beberapa strata berdasarkan pada keadaan habitatnya. Hasil penelitian menunjukkan bahwa densitas plankton di perairan yang diteliti berkisar antara 29-49 individu/L, potensi perikanannya antara 41,3-63,8 kg/ha/th, dan tingkat pemanfaatan sumber daya perikanannya berkisar antara 86\%-133\%. Densitas nisbi (CPUE-jumlah) gillnet dari komunitas ikan di perairan yang diteliti dalam bulan pengamatan (Juli 1998, September 1998, dan Januari 1999) tidak berbeda nyata satu sama lainnya $(a=0,05)$. Akan tetapi densitas nisbinya dalam bobot (CPUE-bobot) dari komunitas ikan dalam bulan Juli 1998 lebih tinggi daripada bulan Januari 1999, sedang nilai densitas tersebut untuk bulan Juli 1998 tidak berbeda nyata dengan September 1998, dan untuk bulan September 1998 tidak berbeda nyata dengan untuk Januari $1999(a=0,05)$. Data dan informasi yang diperoleh diharapkan akan merupakan masukan bagi upaya pengelolaan sumber daya perikanan perairan yang diteliti.
\end{abstract}

ABSTRACT : Fisheries resource potential and its exploitation in the open waters surrounding the tidal paddy fields in South Sumatra. By: Achmad S. Sarnita

Although the total area of open waters in Indonesia is vast, so far, little has been done in managing rational the open water fisheries of the country. This is due to the lack of knowledge in fisheries management of Indonesian inland waters. In July 1998 - January 1999 a study on fishery resources of open waters surrounding the tidal paddy fields in South Sumatera (in the estuary of the River Musi) was conducted to obtain data and information on the potential and exploitation of the fishery resources, and to get preliminary information on aquaculture in acid sulfate soils of the area. The study used survey method, where sample collections and field observations were conducted using stratified sampling procedures. Results of the study showed that densities of plankton communities of the fisheries resources were $24-49$ individuals/L, and their fishery potential and exploitation rate were $41.3-63.8 \mathrm{~kg} / \mathrm{ha} / \mathrm{yr}$ and $86 \%-133 \%$, respectively. Relative densities in number (expressed in CPUE-number) of the fish communities in the studied area during July 1998, September 1998 and January 1999 did not differ significantly one to others $(a=0.05)$. However, the relative density in weight (CPUE-weight) during July 1998 was higher than in January 1999, and that of July 1998 and September 1998 did not differ significantly one to another, and that of September 1998 and January 1999 as well. Data and information obtained were expected to be important inputs for fishery management of the area.

KEYWORDS : tidal area, river fishery, water quality, plankton, fish population

\section{PENDAHULUAN}

Pengelolaan perikanan daerah perairan pasang surut (flood plains) di Indonesia sampai saat ini masih belum banyak dilakukan. Hal ini disebabkan pengetahuan mengenai perikanan perairan pasang surut yang merupakan salah satu jenis perairan umum (open waters), masih sangat terbatas. Di lain pihak potensi perikanan daerah perairan pasang surut cukup besar. Luas lahan perairan pasang surut tercatat sebesar 11,95 juta ha (Djajadiredja et al., 1982) dengan jumlah jenis ikan air tawar yang menghuninya

-) Peneliti pada Pusat Riset Perikanan Tangkap 
diperkirakan sebanyak lebih dari 500 jenis (Ondara, 1982).

Potensi perikanan perairan umum di dan sekitar lahan persawahan pasang surut di muara Sungai Musi, Sumatera Selatan, yang dulunya merupakan daerah rawa banjiran, masih belum banyak diketahui. Perairan ini diperkirakan memegang peranan penting dalam perikanan air tawar di Sumatera Selatan, sebagai salah satu sumber daya ikan air tawar yang cukup besar. Di samping itu beberapa jenis ikan dan udang yang hidup di perairan ini diperkirakan melakukan proses pematangan gonadnya, salah satu proses biologi yang penting bagi sintasan dan perkembangan suatu populasi hewan air.

Usaha budi daya ikan di lahan non-sulfat-masam sudah banyak dilakukan sejak dahulu kala. Namun pada saat ini lahan budi daya ikan yang memenuhi syarat, seperti umumnya terdapat di Jawa, sudah sangat terbatas. Di lain pihak kebutuhan akan protein ikan terus meningkat, sejalan dengan peningkatan jumlah penduduk di negara ini.

Di luar Jawa banyak lahan sulfat-masam yang telah dibuka untuk usaha pertanian (terutama untuk budi daya padi), seperti di Sumatera Selatan, Jambi, Riau, Lampung, Kalimantan Selatan, dan Kalimantan Tengah. Akan tetapi usaha budi daya ikan di lahan sawah bukaan tersebut belum banyak dilakukan, karena teknologi budi dayanya belum banyak diketahui. Di lahan persawahan pasang surut tersebut dapat dilakukan usaha budi daya ikan bersama padi (mina padi), sedang di lahan pekarangannya para petani dapat melakukan usaha budi daya ikan di kolam.

Pengelolaan kolam yang dibangun di lahan rawa sulfat-masam tidak mudah. Tanpa usaha pengelolaan yang tepat usaha budi daya ikan di lahan sulfat-masam dapat menimbulkan kerusakan pada sumber daya lahan tersebut (Husnah et al., 1992). Keasaman akibat oksidasi pada tanah pematang dan dasar kolam yang dibangun di lahan sulfat-masam-potensial membutuhkan penanganan yang tepat (Bloomfield \& Coulter, 1973; Lin, 1986; Gaviria et al., 1986). Sehubungan dengan hal ini, Purnomo \& Singh (1982) berhasil menerapkan metode penetralan dan pembuangan asam melalui teknik reklamasi di lahan sulfat masam daerah pesisir. Lebih jauh Husnah et al. (1992) mengemukakan bahwa pengapuran kolam tanah sulfat-masam sebanyak 1-2 ton/ha dapat memperbaiki kualitas air kolam yang bersangkutan.

Mengingat heterogennya tipologi lahan persawahan pasang surut yang telah lama dibuka di Sumatera Selatan, maka dalam rangka upaya pengembangan budi daya ikan di lahan rawa pasang surut tersebut perlu pertama-tama diketahui potensi sumber daya perikanannya yang dapat dikembangkan untuk usaha budi daya ikan dan jenis hewan air tawar lainnya.

Penelitian mengenai sumber daya ikan di rawa banjiran (flood plains) di Sumatera Selatan telah banyak dilakukan terutama di daerah Kabupaten Ogan Komering Ilir (OKI). Utomo et al. (1993) mencatat sebanyak 64 jenis ikan terdapat di perairan rawa banjiran di Lubuk Lampam, Pedamaran, OKI. Selanjutnya Purnomo et al. (1992) telah mengidentifikasi sekitar 20 jenis ikan dari danau banjiran di tepi Sungai Mahakam (Kalimantan Timur), yaitu di Danau Semayang, Melintang, dan Jempang. Namun demikian penelitian mengenai potensi sumber daya perikanan di muara Sungai Musi sebegitu jauh belum dilakukan

Penelitian potensi dan tingkat pemanfaatan sumber daya ikan di lahan persawahan pasang surut Sumatera Selatan dan perairan umum sekitarnya kali ini dilakukan dengan tujuan untuk mendapatkan data dan informasi mengenai potensi dan tingkat pemanfaatan sumber daya perikanan di lahan pasang surut muara Sungai Musi. Hasil penelitian ini akan merupakan data dasar (data base) mengenai perikanan di lahan yang bersangkutan, yang selanjutnya dapat dipergunakan untuk merakit alternatif pengelolaan perikanan di wilayah tersebut.

\section{BAHAN DAN METODE}

Penelitian telah dilakukan di perairan lahan persawahan pasang surut Sumatera Selatan dan perairan sungai sekitarnya (muara Sungai Musi) (Gambar 1).

Metode penelitian yang digunakan adalah metode survai. Pengambilan sampel (contoh) dilakukan dengan menggunakan metode pengambilan sampel berstrata (Nielsen \& Johnson, 1985). Dalam hal ini wilayah perairan yang diteliti dibagi menjadi 6 strata berdasarkan pada keadaan habitatnya dan pemanfaatan lahan sekitarnya (Gambar 1). Keenam strata tersebut adalah: a) perairan muara Sungai Musi (Air Upang); b) daerah persawahan pasang surut Karang Agung Ulu; c) perairan Sungai Sebalik, d) perairan Sungai Lalan; e) daerah persawahan pasang surut Telang; f) daerah persawahan pasang surut Sugihan Kiri. Tiga strata di antaranya, yaitu daerah persawahan pasang surut Karang Agung Ulu, Telang, dan Sugihan Kiri, dibagi lagi masing-masing menjadi 2 sub-strata.

Selanjutnya pada masing-masing stratum ditentukan satu stasiun pengamatan, dan pada masing masing stasiun pengamatan diambil sampel air, fauna, 


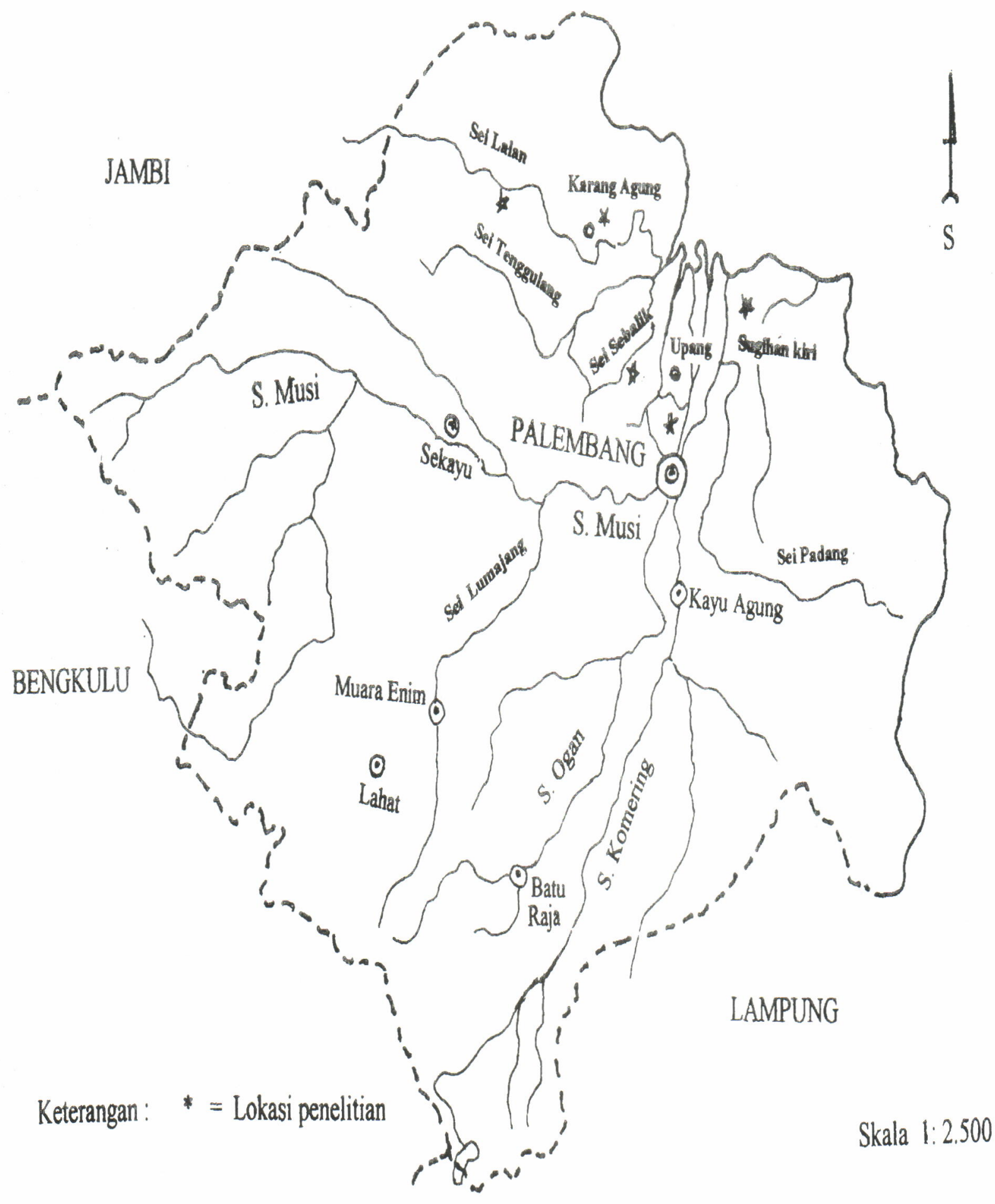

Gambar 1. Propinsi Sumatera Selatan

Figure 1. South Sumatra Province 
peralihan (23-30 September 1998), dan musim hujan (3-10 Januari 1999).

Parameter yang diteliti meliputi parameter kualitas air, plankton, tumbuhan air, produktivitas primer, komunitas ikan (faktor kondisi, hubungan panjang bobot), hasil tangkapan nelayan setempat, dan tingkat pemanfaatan sumber daya perikanannya.

Parameter kualitas air yang diamati meliputi kecerahan, suhu air, $\mathrm{pH}$, kadar oksigen, dan $\mathrm{CO}_{2}$ serta alkalinitas. Analisis parameter kualitas air hanya dilakukan untuk air permukaan. Parameter kualitas air dianalisis secara titrimetrik (Golterman \& Clymo, 1970; Boyd, 1990) atau secara elektronik memakai alat Water quality checker, Mini spectronic Bausch and Lomb dan YSI Oxygen meter

Komunitas plankton dikumpulkan dengan memakai plankton net no. $24(60 \mu \mathrm{m})$, diawetkan dengan alkohol $70 \%$ atau formalin $4 \%$, untuk kemudian dianalisis di laboratorium. Tumbuhan air diidentifikasi jenisnya, ditentukan penyebarannya serta diestimasi besar populasinya (luas daerah penyebarannya).

Produktivitas primer dari perairan yang diteliti ditentukan dengan metode botol terang botol gelap (Cole, 1988; Boyd, 1990). Produktivitas primer (PP) dihitung dengan menggunakan formula dari Cox (1976) sebagai berikut:

$$
P P=375,4(B T-B G): 1,2 T
$$

dengan:

PP =produktivitas primer (gross primary productivity) dalam mgC/L/jam

BT =kadar oksigen dalam botol terang $(\mathrm{mg} / \mathrm{L})$

BG =kadar oksigen dalam botol gelap $(\mathrm{mg} / \mathrm{L})$

$T \quad=$ waktu inkubasi (jam)

Potensi produksi ikan dari perairan tergenang yang diteliti (kolam) ditentukan berdasarkan model estimasi dari Almazan \& Boyd (1978)

dengan:

$$
\operatorname{Ln}(y)=0,0013(x) \operatorname{Ln}(x)+3,4871
$$

$y=$ potensi produksi ikan $(\mathrm{kg} / \mathrm{ha} / \mathrm{th})$

$\mathrm{x}=$ produktivitas primer $\left(\mathrm{gC} / \mathrm{m}^{2} / \mathrm{th}\right)$

Untuk perairan yang mengalir yang diteliti (saluran irigasi dan sungai), potensi produksi ikannya ditentukan berdasarkan rumus Leger-Huet (Welcome, 1983) :

$$
\mathrm{K}=\mathrm{BLK}
$$

dengan:

$\mathrm{K}=$ potensi produksi ikan $(\mathrm{kg} / \mathrm{km})$

$\mathrm{B}=$ kapasitas biogenik $k=$ koefisien produksi

$L=$ lebar rata-rata perairan sungai

Karakteristik populasi ikan, terutama ikan ekonomis penting, ditentukan berdasarkan data hasil percobaan penangkapan dengan menggunakan 2 jaring percobaan (experimental gill-net), masingmasing berukuran mata jaring antara $2,5 \mathrm{~cm} ; 5 \mathrm{~cm}$; dan $7,5 \mathrm{~cm}$ (stretch sizes), panjang $50 \mathrm{~m}$ dan kedalaman $2 \mathrm{~m}$, serta dari hasil tangkapan nelayan. Pemasangan kedua jaring percobaan dilakukan pada masing-masing stasiun pengamatan setiap kali survai sebanyak 2 kali (2 malam). Jaring tersebut dipasang pada sore hari dan kemudian diangkat pada pagi hari (lama jaring dipasang $=12-14$ jam). I $\mathrm{kan}$ yang tertangkap dengan jaring percobaan serta sampel ikan dari hasil tangkapan nelayan diidentifikasi jenisnya, diukur panjang dan ditimbang bobotnya tiap individu, untuk selanjutnya dianalisa di laboratorium. Faktor kondisi (condition factor) dari masing-masing individu ikan dihitung berdasarkan rumus Fulton (Ricker, 1987) sebagai berikut:

$$
\mathrm{Kn}=100 \mathrm{~W} / \mathrm{L}^{3}
$$

dengan:

$\mathrm{Kn}=$ Faktor kondisi

$\mathrm{W}=$ bobot ikan $(\mathrm{g})$

$\mathrm{L} \quad$ = panjang total ikan $(\mathrm{cm})$

Pertumbuhan nisbi dari ikan yang diamati digambarkan (diformulasikan) dalam bentuk hubungan panjang dan bobot ikan menurut persamaan regresi dari Ricker (1987) sebagai berikut:

$$
\log (W)=a+b \log (L)
$$

dengan:

W

$=$ bobot ikan $(\mathrm{g})$

$\mathrm{L} \quad \quad=$ panjang total ikan $(\mathrm{cm})$

$\mathrm{a}$ dan $\mathrm{b} \quad$ = koefisien regresi

Hasil tangkapan nelayan setempat dihitung (diestimasi) berdasarkan data/informasi yang dikumpulkan melalui wawancara dengan nelayan dan data dari Dinas Perikanan setempat. Tingkat pemanfaatan sumber daya ikan (TP) dihitung sebagai berikut:

$\operatorname{TP}(\%)=$ total hasil tangkapan $/$ potensi produksi $x$
$100 \%$

Data yang diperoleh dianalisis secara statistik dengan menggunakan Program SAS (SAS Inst. Inc., 1985). Rancangan percobaan adalah Rancangan Acak Blok (Randomized Block Design) (Petersen, 1985), dengan stasiun pengamatan sebagai perlakuan dan bulan pengamatan (Juli 1998, September 1998 dan Januari 1999) sebagai blok. 


\section{HASIL DAN BAHASAN}

\section{Kualitas air}

Hasil analisis beberapa parameter kualitas air tercantum pada Tabel 1. Dari Tabel 1 terlihat bahwa secara umum tidak terdapat perbedaan yang berarti dalam hal kualitas air dari ke 9 habitat perairan (lokasi pengambilan sample) yang diperiksa (Muara Sungai Musi, Sungai Lalan, Sungai Sebalik, serta saluran irigasi dan kolam di lahan persawahan pasang surut Karang Agung Ulu, Telang, dan Sugihan Kiri). Perbedaan terlihat pada kadar $\mathrm{CO}_{2}$ saja, di mana kadar yang tinggi dengan variasi yang tinggi pula teramati di muara Sungai Musi.

Tabel1. Kualitas air di Sungai Sebalik, muara Sungai Musi, Sungai Lalan, saluran irigasi, dan kolam pekarangan di lahan persawahan pasang surut Sumatera Selatan (Juli 1998, September 1998, dan Januari 1999)

Table 1. Water quality in the River Sebalik, Estuary of the Musi River, River Lalan, irrigation canals, and fish ponds in tidal paddy fields of South Sumatra (July 1998, September 1998, and January 1999)

\begin{tabular}{|c|c|c|c|c|c|c|c|c|c|}
\hline \multirow[b]{2}{*}{$\begin{array}{l}\text { Kualitas air } \\
\text { Water quality }\end{array}$} & \multicolumn{3}{|c|}{ Lokasi/Location } & \multicolumn{2}{|c|}{ Telang } & \multicolumn{2}{|c|}{$\begin{array}{l}\text { Karang } \\
\text { Agung Ulu }\end{array}$} & \multicolumn{2}{|c|}{$\begin{array}{l}\text { Sugihan } \\
\text { Kiri }\end{array}$} \\
\hline & $\begin{array}{c}\text { Muara S. Musi } \\
\text { Estuary of } \\
\text { the River } \\
\text { Musi }\end{array}$ & $\begin{array}{l}\text { S.Sebalik } \\
\text { River } \\
\text { Sebalik }\end{array}$ & $\begin{array}{l}\text { S. Lalan } \\
\text { River } \\
\text { lalan }\end{array}$ & SIT & KLM & SIT & KLM & SIT & KLM \\
\hline $\begin{array}{l}\text { Juli (July) 1998: } \\
\text { Kecerahan } \\
(\text { Transparency) }(\mathrm{cm})\end{array}$ & 112 & 210 & 80 & 30 & 40 & 70 & 30 & 75 & 40 \\
\hline Suhu air (Water temp. ) $\left({ }^{\circ} \mathrm{C}\right)$ & 31 & 31 & 31 & 31 & 29 & 32 & 30 & 32 & 30 \\
\hline $\mathrm{pH}$ & 6 & 6 & 5 & 5 & 6 & 5 & 6.5 & 5 & 6 \\
\hline Oksigen $(\mathrm{DO})(\mathrm{mg} / \mathrm{L})$ & 7 & 6 & 7 & 3 & 6 & 4 & 6 & 6 & 8 \\
\hline $\mathrm{CO}_{2}(\mathrm{mg} / \mathrm{L})$ & 6 & 5 & 15 & 7 & 6 & 7 & 5 & 3 & 8 \\
\hline $\begin{array}{l}\text { Alkalinitas } \\
(\text { Alkalinity })\left(\mathrm{mgCaCO}_{3} / \mathrm{L}\right)\end{array}$ & 4 & 4 & 4 & 7 & 8 & 5 & 10 & 7 & 8 \\
\hline $\begin{array}{l}\text { September } 1998: \\
\text { Kecerahan } \\
(\text { Transparency) }(\mathrm{cm})\end{array}$ & 45 & 45 & 60 & 15 & 30 & 50 & 25 & 15 & 30 \\
\hline Suhu air (Water temp. ) $\left({ }^{\circ} \mathrm{C}\right)$ & 30 & 30 & 30 & 30 & 26 & 31 & 28 & 30 & 28 \\
\hline $\mathrm{pH}$ & 4 & 4 & 4 & 4 & 4 & 4 & 4 & 4 & 4 \\
\hline Oksigen (DO)(mg/L) & 4 & 3 & 6 & 2 & 4 & 3 & 4 & 4 & 5 \\
\hline $\mathrm{CO}_{2}(\mathrm{mg} / \mathrm{L})$ & 16 & 17 & 16 & 8 & 10 & 8 & 8 & 8 & 10 \\
\hline $\begin{array}{l}\text { Alkalinitas } \\
(\text { Alkalinity })\left(\mathrm{mgCaCO}_{3} / \mathrm{L}\right)\end{array}$ & 3 & 2 & 2 & 6 & 6 & 4 & 4 & 4 & 5 \\
\hline $\begin{array}{l}\text { Januari (January) 1999: } \\
\text { Kecerahan } \\
\text { (Transparency) }(\mathrm{cm})\end{array}$ & 120 & 220 & 65 & 25 & 32 & 60 & 35 & 80 & 35 \\
\hline Suhu air (Water temp. ) $\left({ }^{\circ} \mathrm{C}\right)$ & 30 & 30 & 30.5 & 31 & 28 & 31 & 29 & 31 & 5 \\
\hline $\mathrm{pH}$ & 5.5 & 5 & 4 & 4.5 & 5 & 5 & 6 & 5 & 5 \\
\hline Oksigen (DO)(mg/L) & 6 & 5 & 6.5 & 3 & 5 & 3 & 5 & 5 & 7 \\
\hline $\mathrm{CO}_{2}(\mathrm{mg} / \mathrm{L})$ & 8 & 10 & 14 & 7 & 5 & 7 & 6 & 2 & 9 \\
\hline $\begin{array}{l}\text { Alkalinitas } \\
(\text { Alkalinity })\left(\mathrm{mgCaCO}_{3} / \mathrm{L}\right)\end{array}$ & 4 & 4 & 3 & 6.5 & 7 & 4 & 9 & 6 & \\
\hline
\end{tabular}

\section{Catatan/Note:}

SIT = Saluran irigasi tersier/Tertiary irrigation canal

$\mathrm{KLM}=\mathrm{Kolam} /$ pond 
Bila dibandingkan antara sungai utama (Sungai Musi, Sungai Sebalik, dan Sungai Lalan) dengan saluran irigasinya, ternyata bahwa $\mathrm{pH}$ air sungai utama lebih tinggi. Di lain pihak pH kolam lebih tinggi dari sungai utama. Hal ini disebabkan karena kolam-kolam tersebut diberi pupuk kapur $\left(\mathrm{CaCO}_{3}\right)$. Nampaknya untuk pengembangan budi daya ikan di lahan persawahan pasang surut Sumatera Selatan, $\mathrm{pH}$ air akan merupakan kendala yang paling utama di dalam hal kualitas air.

Mengingat kualitas air, terutama $\mathrm{pH}$ dan alkalinitas yang kurang menguntungkan bagi usaha budi daya ikan, pengembangan usaha budi daya ikan di kolam dan di sawah (mina padi) di lokasi tersebut di atas perlu didahului dengan proses ameliorisasi lahan, terutama untuk meningkatkan $\mathrm{pH}$ air. Pembilasan lahan budi daya ikan dengan air dari saluran primer yang sedikit lebih tinggi pH-nya perlu dilakukan dengan diikuti oleh pemupukan kapur. Di samping itu cara penggalian kolam perlu dilakukan dengan hati-hati dengan mengikuti teknik pembuatan kolam di lahan tanah bersulfat masam. Nampaknya pembuatan kolam yang dasar dan dindingnya dilapisi plastik dapat diterapkan di sini setelah melalui pengujian-pengujian yang seksama. Dalam hal ini usaha budi dayanya akan lebih mengarah kepada usaha budi daya ikan di air tergenang (tadah hujan) yang hemat air.

\section{Plankton}

Hasil analisis komunitas plankton di perairan muara Sungai Musi serta saluran irigasinya disajikan pada Tabel 2 .

Dari Tabel 2 terlihat bahwa densitas plankton di seluruh perairan yang diteliti tidak tinggi. Densitas yang terendah ( 24 ind./L) dijumpai pada saluran irigasi tersier di Telang, sedang yang tertinggi pada kolam ikan di Karang Agung Ulu (49 ind./L). Densitas fitoplankton relatif densitasnya lebih tinggi dibanding dengan densitas zooplankton, yang hampir merata untuk seluruh perairan

Densitas plankton antar bulan-bulan pengamatan (Juli 1998, September 1998, dan Januari 1999) tidak berbeda nyata (Tabel 3). Dengan perkataan lain tidak terdapat pengaruh dari bulan pengamatan terhadap densitas plankton.

\section{Produktivitas primer}

Produktivitas primer dari perairan yang diteliti berkisar antara $16,2-38,0 \mathrm{mg} \mathrm{C} / \mathrm{m}^{2} / \mathrm{jam}$. Nilai produktivitas primer yang tertinggi $\left(38,0 \mathrm{mgC} / \mathrm{m}^{2} / \mathrm{jam}\right)$ dicapai oleh kolam di Karang Agung Ulu, sedang yang terendah (16,2 mgC/m²/jam) dijumpai di saluran irigasi di lahan persawahan di Telang.
Uji T (T-test) terhadap produktivitas primer (Tabel 4) menunjukkan bahwa nilai produktivitas primer di kolam pekarangan lebih besar daripada di saluran irigasinya ("=0.05). Hal ini disebabkan pertumbuhan fitoplankton lebih baik di kolam pekarangan (air tergenang) daripada di saluran irigasi (air mengalir).

Dengan asumsi bahwa proses fotosintesis dapat berlangsung sekitar 8 jam/hari dan 360 hari/th, serta berdasarkan rumus estimasi potensi produksi ikan dari Almazan \& Boyd (1978), maka potensi produksi ikan dari kolam di lahan persawahan pasang surut muara Sungai Musi berkisar antara 46-64 kg/ha/th .

\section{Tumbuhan air}

Tumbuhan air (gulma air) yang dapat dikumpulkan di lokasi penelitian tidaklah begitu beragam. Jenis tumbuhan yang ditemukan di tepi ketiga sungai yang diteliti terdiri atas: Polygonum dan rumput-rumputan (Scirpus, Cyperus, Juncus, Ludwigia dan Cladium). Pada saluran-saluran sekunder, tersier dan kwarter serta di sawah-sawah, di samping tumbuhan air dari jenis Polygonum sering ditemukan rumputrumputan (Eleocharis, Fimbristylis, Scirpus, Eriocaulon, Paspalum, Amaranthus), paku air (Ceratopteris thalictoides), eceng (Monochoria hastata, $M$. vaginalis), genjer (Limnocharis flava), ilung (Eichhornia crassipes), kiambang (Pistia, Salvinia, Lemna, Azolla), ganggang (Utricularia, Hydrilla, Ceratophyllum, Cabomba), dan teratai (Nymphea, Nelumbo).

Populasi tumbuhan air di lahan sawah pasang surut dan perairan sungai di muara Sungai Musi tersebut tidak besar, hanya pada beberapa saluran tersier tumbuhan air menutupi seluruh saluran. Populasi tumbuhan air di perairan yang diteliti didominasi oleh rumput-rumputan dan ganggang. Pada saluran irigasi umumnya ditemukan lebih banyak tumbuhan air. Hal ini disebabkan arus air di saluran irigasi umumnya lebih lemah daripada di sungai utamanya (batanghari).

\section{Populasi Ikan}

Komunitas ikan yang menghuni perairan umum sekitar lahan persawahan pasang surut Sumatera Selatan terdiri atas 34 jenis ikan dan 1 jenis udang; 7 jenis di antaranya adalah ikan predator. Di perairan muara Sungai Musi terdapat 28 jenis ikan, di Sungai Sebalik tertangkap 22 jenis, di Sungai Lalan terdapat 20 jenis, dan di saluran irigasi sekunder ditemukan 15 jenis ikan (Lampiran 1). Komposisi jenis ikan di perairan umum yang diteliti didominasi oleh jenis ikan non-predator (Lampiran 1).

Hasil percobaan penangkapan dengan menggunakan jaring percobaan (experimental gill-net) dapat dilihat pada Lampiran II. Hasil analisis statistik 
Tabel2. Densitas individu plankton (ind./L) di perairan muara Sungai Sebalik, Sungai Lalan serta Saluran Irigasi Tersier dan kolam pekarangan di lahan persawahan pasang surut Sumatera Selatan

Table 2. Plankton density (ind./L) in the estuary of the Musi River, River Sebalik, River Lalan, dan tertiary irrigation canals and back yard ponds in the tidal paddy fields of South Sumatra

\begin{tabular}{|c|c|c|c|c|c|c|c|c|c|}
\hline \multirow[b]{2}{*}{$\begin{array}{c}\text { Filum/Kelas } \\
\text { (Phyllum/Class }\end{array}$} & \multicolumn{3}{|c|}{ Lokasi/Location } & \multicolumn{2}{|c|}{ Telang } & \multicolumn{2}{|c|}{$\begin{array}{l}\text { Karang } \\
\text { Agung Ulu }\end{array}$} & \multicolumn{2}{|c|}{$\begin{array}{l}\text { Sugihan } \\
\text { Kiri }\end{array}$} \\
\hline & $\begin{array}{l}\text { Muara S. Musi } \\
\text { Estuary of the } \\
\text { River Musi }\end{array}$ & $\begin{array}{l}\text { S.Sebalik } \\
\text { River } \\
\text { Sebalik }\end{array}$ & $\begin{array}{l}\text { S. Lalan } \\
\text { River } \\
\text { lalan }\end{array}$ & SIT & KL.MI & SIT & KLM & SIT & KLM \\
\hline Juli (July) 1998 : & 9 & 7 & 9 & 6 & 10 & 8 & 11 & 7 & 9 \\
\hline Cyanophyceae & 11 & 10 & 10 & 8 & 10 & 9 & 12 & 7 & 8 \\
\hline Chlorophyceae & 3 & 2 & 1 & 0 & 2 & 4 & 4 & 2 & 2 \\
\hline Dinophyceae & 7 & 6 & 8 & 6 & 11 & 8 & 10 & 5 & 7 \\
\hline Bacillariophyceae & 2 & 2 & 1 & 1 & 2 & 2 & 2 & 1 & 2 \\
\hline Euglenophyceae & 2 & 2 & 4 & 2 & 2 & 4 & 1 & 2 & 3 \\
\hline Protozoa & 2 & 1 & 1 & 1 & 1 & 2 & 3 & 2 & 2 \\
\hline Rotifera & 1 & 1 & 0 & 0 & 1 & 1 & 1 & 1 & 0 \\
\hline Cladocera & 0 & 0 & 0 & 0 & 0 & 1 & 1 & 1 & 1 \\
\hline Copepoda & 0 & 0 & 1 & 0 & 1 & 1 & 1 & 0 & 0 \\
\hline Ostracoda & 38 & 31 & 35 & 24 & 40 & 40 & 46 & 28 & 34 \\
\hline $\begin{array}{l}\text { Jumlah (ind./L) } \\
\text { Produktivitas primer (Primary } \\
\text { productivity) (mgC/m²/jam) }\end{array}$ & 23.5 & 19.8 & 21.3 & 16.2 & 25.8 & 22.8 & 37.8 & 27 & 21.6 \\
\hline September 1998 : & 10 & 8 & 7 & 6 & 11 & 8 & 11 & 7 & 10 \\
\hline Cyanophyceae & 10 & 9 & 12 & 7 & 9 & 10 & 12 & 8 & 8 \\
\hline Chlorophyceae & 4 & 3 & 2 & 0 & 2 & 3 & 4 & 2 & 2 \\
\hline Dinophyceae & 8 & 6 & 8 & 6 & 11 & 8 & 10 & 6 & 8 \\
\hline Bacillariophyceae & 2 & 2 & 2 & 1 & 2 & 3 & 2 & 1 & 2 \\
\hline Euglenophyceae & 2 & 2 & 4 & 3 & 2 & 4 & 2 & 2 & 3 \\
\hline Protozoa & 2 & 1 & 2 & 2 & 1 & 2 & 4 & 2 & 2 \\
\hline Rotifera & 1 & 1 & 0 & 1 & 1 & 1 & 2 & 1 & 1 \\
\hline Cladocera & 0 & 1 & 1 & 1 & 1 & 1 & 1 & 1 & 1 \\
\hline Copepoda & 1 & 0 & 1 & 0 & 1 & 1 & 1 & 0 & 1 \\
\hline Ostracoda & 40 & 33 & 39 & 27 & 41 & 41 & 49 & 30 & 38 \\
\hline $\begin{array}{l}\text { Jumlah (ind./L) } \\
\text { Produktivitas primer (Primary } \\
\left.\text { productivity) ( } \mathrm{mgC} / \mathrm{m}^{2} / \mathrm{jam}\right)\end{array}$ & 24.1 & 20.2 & 21.6 & 16.7 & 26 & 23.1 & 38 & 27.1 & 22.2 \\
\hline Januari (January) 1999 : & & & & & & & & & \\
\hline Cyanophyceae & 9 & 8 & 9 & 7 & 11 & 9 & 10 & 7 & 9 \\
\hline Chlorophyceae & 11 & 11 & 9 & 9 & 10 & 9 & 12 & 9 & 10 \\
\hline Dinophyceae & 5 & 2 & 3 & 0 & 2 & 2 & 3 & 2 & 2 \\
\hline Bacillariophyceae & 8 & 8 & 8 & 5 & 12 & 8 & 12 & 6 & 7 \\
\hline Euglenophyceae & 2 & 2 & 1 & 1 & 2 & 2 & 3 & 2 & 2 \\
\hline Protozoa & 1 & 3 & 3 & 2 & 2 & 4 & 1 & 2 & 3 \\
\hline Rotifera & 3 & 1 & 2 & 2 & 1 & 2 & 3 & 2 & 2 \\
\hline Cladocera & 1 & 1 & 1 & 1 & 1 & 2 & 1 & 2 & 1 \\
\hline Copepoda & 1 & 0 & 1 & 0 & 1 & 1 & 1 & 1 & 1 \\
\hline Ostracoda & 0 & 1 & 1 & 1 & 1 & 1 & 1 & 0 & 1 \\
\hline Jumlah (ind./L) & 41 & 37 & 38 & 28 & 43 & 40 & 47 & 33 & 38 \\
\hline $\begin{array}{l}\text { Produktivitas primer (Primary } \\
\left.\text { productivity) ( } \mathrm{mgC} / \mathrm{m}^{2} / \mathrm{jam}\right)\end{array}$ & 24.6 & 20.9 & 21.5 & 17.1 & 26.2 & 23.2 & 37.8 & 28.3 & 22.3 \\
\hline
\end{tabular}


Tabel 3. Nilai rataan dari jumlah plankton pada setiap bulan pengamatan

Table 3. Mean of plankton density (in number) in each month of observation

\begin{tabular}{lccc}
\hline $\begin{array}{c}\text { Bulan pengamatan } \\
\text { Observation time }\end{array}$ & $\begin{array}{c}\text { Nilai rataan } \\
\text { Mean }\end{array}$ & $\begin{array}{c}\text { Pengelompokan Duncan } \\
\text { Duncan grouping }\end{array}$ & N \\
\hline Juli (July) 1998 & 34.0 & A & 9 \\
September 1998 & 37.6 & A & 9 \\
Januari (January) 1999 & 38.3 & A & 9 \\
\hline
\end{tabular}

Catatan: Nilai rataan yang diikuti oleh huruf yang sama tidak berbeda nyata $(P>0,05)$

Note: Means followed by same letter are not significantly different $(P>0.05)$

Tabel 4. Nilai rataan produktivitas primer di perairan yang diteliti $\left(\mathrm{mgC} / \mathrm{m}^{2} / \mathrm{jam}\right)$

Table 4. Means of primary productivity of plankton in the studied waters $\left(\mathrm{mgCl} / \mathrm{m}^{2} / \mathrm{hr}\right)$

\begin{tabular}{lccccc}
\hline \multicolumn{1}{c}{$\begin{array}{c}\text { Sistem } \\
\text { System }\end{array}$} & $\begin{array}{c}\text { Rataan } \\
\text { Mean }\end{array}$ & $\mathbf{N}$ & $\begin{array}{c}\text { Simpangan baku } \\
\text { Standard deviation }\end{array}$ & T $\begin{array}{c}\text { Peluang }>T \\
\text { Probability }>T\end{array}$ \\
\hline Kolam (Pond) & 28.6 & 9 & 7.14 & 2.2 & 0.046 \\
Saluran irigasi (Irrigation canal) & 22.4 & 9 & 4.72 & 2.2 & 0.044 \\
\hline
\end{tabular}

dari hasil percobaan penangkapan tersebut tertera pada Tabel 5.

Tabel 5. Nilai rataan CPUE (jumlah ekor/jaring percobaan malam dan bobotjjaring percobaan malam) dari hasil percobaan penangkapan dengan jaring percobaan di perairan muara Sungai Musi, Sungai Sebalik, sungai Lalan dan Saluran Irigasi Sekunder dalam Juli 1998, September 1998, dan Januari 1999

Table 5. Mean CPUE (number/experimental net-night and weight/experimental net-night) of the fishing experiment using experimental gill-net in the River Musi, Sebalik, Lalan and Secondary Irrigation Canal during July 1998, September 1998 and January 1999

\begin{tabular}{lccccccc}
\hline \multicolumn{1}{c}{ CPUE } & \multicolumn{2}{c}{$\begin{array}{c}\text { Jumlah dalam ekor } \\
\text { Number in individual }\end{array}$} & \multicolumn{4}{c}{$\begin{array}{c}\text { Bobot dalam g } \\
\text { Weight in g }\end{array}$} \\
\hline Bulan-tahun (Month-Year) & Rataan (Mean) & Std. & N & Rataan (Mean) & Std. & N \\
\hline Juli (July) 1998 & $13.4 \mathrm{a}$ & 7.6 & 4 & $1319.9 \mathrm{a}$ & 733.6 & 4 \\
September 1998 & $7.4 \mathrm{a}$ & 1.1 & 4 & $698.3 \mathrm{ab}$ & 127.7 & 4 \\
Januari (January) 1999 & $7.1 \mathrm{a}$ & 1.1 & 4 & $445.6 \mathrm{~b}$ & 169.8 & 4 \\
\hline
\end{tabular}

Catatan/Note:

CPUE = Hasil tangkapan per satuan usaha/CPUE = Catch per Unit of Effort

Std $=$ Simpangan baku/Std $=$ Standard deviation

$\mathrm{N}=$ Jumlah ulangan $/ \mathrm{N}=$ Replication

Nilai Rataan yang diikuti oleh huruf yang sama tidak berbeda nyata $(a=0,05)$

Means followed by the same letter are not significantly different $(a=0.05)$

Dari Tabel 5 dapat dilihat bahwa densitas nisbi (CPUE dalam jumlah ekor) dari komunitas ikan di perairan ini dalam bulan Juli 1998, September 1998 dan Januari 1999 tidak berbeda nyata satu sama lainnya. Akan tetapi densitas nisbi (dalam CPUEbobot) dari komunitas ikan pada bulan Juli 1998 lebih besar dari densitas nisbinya pada bulan Januari 1999 $(a=0,05)$, sedangkan densitas nisbi (CPUE-bobot) dalam bulan Juli 1998 tidak berbeda nyata dengan densitas nisbi pada bulan September 1998, dan densitas nisbinya pada bulan September 1998 tidak berbeda nyata dengan pada bulan Januari $1999(a=$ $0,05)$. CPUE-bobot yang tertinggi pada bulan Juli 1998 (musim kemarau) menunjukkan bahwa stok ikan pada saat itu didominasi oleh individu ikan yang berukuran besar.

Hubungan panjang-bobot (pertumbuhan nisbi) dari 7 jenis ikan yang dapat dikumpulkan baik dari hasil percobaan penangkapan maupun dari hasil tangkapan nelayan setempat tertera pada Tabel 6 . Hubungan panjang-bobot dari ketujuh jenis ikan tersebut 
Tabel6. Hubungan panjang-bobot dari 7 jenis ikan di perairan umum sekitar lahan sawah pasang surut Sumatera Selatan

Table 6. Length-weight relationship of 7 fish species in open waters around the area of tidal paddy fields in South Sumatra

\begin{tabular}{|c|c|c|c|c|c|}
\hline \multirow{2}{*}{$\begin{array}{l}\text { Jenis ikan } \\
\text { Species }\end{array}$} & \multirow{2}{*}{$\begin{array}{c}\text { Kisaran } \\
\text { panjang } \\
\text { Length } \\
\text { interval }(\mathrm{cm})\end{array}$} & \multirow{2}{*}{$\begin{array}{c}\text { Kisaran } \\
\text { bobot } \\
\text { Weight } \\
\text { interval (g) }\end{array}$} & \multicolumn{3}{|c|}{$\begin{array}{l}\text { Hubungan panjang-bobot } \\
\text { Length-weight relationship }\end{array}$} \\
\hline & & & $\begin{array}{l}\text { Persamaan regresi } \\
\text { Regression equation }\end{array}$ & $\mathbf{R}^{2}$ & $\mathbf{N}$ \\
\hline Helostoma temmincki & $6.0-11.4$ & $5.0-26.5$ & $\log W=-1.376+2.660 \log (L)$ & 0.994 & 52 \\
\hline Chana micropeltes & $8.2-21.6$ & $9.5-76.0$ & $\log W=-0.946+2.120 \log (L)$ & 0.999 & 29 \\
\hline Mystus sp. & $14.8-23.5$ & $65.5-104.5$ & $\log W=0.640+1.005 \log (L)$ & 0.999 & 26 \\
\hline Tricogaster pectoralis & $6.3-11.2$ & $8.0-41.5$ & $\log W=-1.446+2.920 \log (L)$ & 0.997 & 85 \\
\hline Puntius schwanefeldi & $11.2-20.4$ & $40.5-228.0$ & $\log W=-1.410+2.878 \log (L)$ & 0.999 & 62 \\
\hline Osteochilus kelabau & 8.2-19.9 & $16.5-146.5$ & $\log W=-1.044+2.471 \log (L)$ & 0.999 & 24 \\
\hline Anabas testudineus & $7.8-12.9$ & $8.0-32.0$ & $\log W=-1.509+2.712 \log (L)$ & 0.998 & 76 \\
\hline
\end{tabular}

Catatan/note:

$\mathrm{R}^{2}=$ koefisien diterminasi/Coefficient of determination

$\mathrm{N}=$ Jumlah sampel ikan/Number of fish sample

menunjukkan pertumbuhan yang bersifat allometrik (b $<3$ pada $a=0,01$ ), yang berarti bahwa pertumbuhan panjang lebih besar dari pertumbuhan
Potensi produksi ikan di perairan mengalir (sungai dan saluran irigasi) di lahan persawahan pasang surut

Tabel 7. Faktor kondisi (Kn) dari 7 jenis ikan di perairan umum sekitar lahan sawah pasang surut di Sumatera Selatan

Table 7. Condition factor $(K n)$ of 7 fish species in open waters surrounding the tidal paddy fields of South Sumatra

\begin{tabular}{lcccc}
\hline \multirow{2}{*}{$\begin{array}{c}\text { Jenis ikan } \\
\text { Fish species }\end{array}$} & \multicolumn{4}{c}{ Faktor kondisi (Condition factor) } \\
\cline { 2 - 5 } & $\begin{array}{c}\text { Kisaran } \\
\text { Interval }\end{array}$ & $\begin{array}{c}\text { Rataan } \\
\text { Mean }\end{array}$ & STD & N \\
\hline Helostoma temmincki & $1.86-2.99$ & 2.34 & 0.40 & 52 \\
Chana micropeltes & $0.75-1.77$ & 1.12 & 0.30 & 29 \\
Mystus sp. & $0.80-2.02$ & 1.48 & 0.32 & 26 \\
Tricogaster pectoralis & $2.75-3.24$ & 3.02 & 0.09 & 85 \\
Puntius schwanefeldi & $2.69-2.90$ & 2.8 & 0.05 & 62 \\
Osteochilus kelabau & $1.86-2.99$ & 2.34 & 0.40 & 24 \\
Anabas testudineus & $1.48-1.82$ & 1.58 & 0.07 & 76 \\
\hline STD = Deviasi baku/Standard deviation & & \\
$\mathrm{N} \quad=$ Jumlah sampel/number of sample & &
\end{tabular}

tinggi badannya. Hal ini merupakan hal yang umum terjadi di suatu perairan umum.

Faktor kondisi dari beberapa jenis ikan yang diamati boleh dikatakan hampir sama (Tabel 7). Hal ini berarti bahwa faktor lingkungan perairan memberikan pengaruh/dampak yang sama terhadap ketujuh jenis ikan yang tertera pada Tabel 7 tersebut.
Sumatera Selatan berdasarkan rumus Leger-Huet tertera pada Tabel 8 di bawah ini.

\section{Pengelolaan sumber daya dan budi daya ikan}

Usaha penangkapan ikan di perairan umum (termasuk sungai dan perairan rawa) di Sumatera Selatan telah sejak lama dilakukan. Demikian pula 
Tabel 8. Potensi produksi ikan dari muara S. Musi, Sungai Lalan, Sungai Sebalik, dan Saluran Irigasi Tersier di daerah persawahan pasang surut Sumatera Selatan

Table 8. Potential fish production of the River Musi Estuary, the River Lalan, the River Sebalik, and Tertiary Irrigation Canals of the tidal paddy fields in South Sumatra

\begin{tabular}{lccccc}
\hline \multicolumn{1}{c}{ Perairan (Water body) } & B & L (m) & k & K (kg/ha \\
\hline Muara S. Musi (Estuary of the Musi River) & 4 & 500 & 7 & 280 \\
Sungai Lalan (The River Lalan) & 5 & 50 & 7 & 350 \\
Sungai Sebalik (The River Sebalik) & 5 & 60 & 7 & 350 \\
Saluran Irigasi Tersier (Tertiary Irrigation Canal) & 3 & 2 & 7 & 210 \\
\hline
\end{tabular}

Catatan/Note:

$\mathrm{B}=$ Kapasitas biogenik/Biogenic capacity in unit

$L=$ Lebar rata-rata perairan/Average river width in $m$

$\mathrm{k}=$ Koefisien produksi ikan/Coefficient of productivity in unit

$\mathrm{K}=$ Potensi produksi ikan/Potential fish production in $\mathrm{kg} / \mathrm{ha}$

halnya dengan usaha penangkapan ikan di muara Sungai Musi. Pada 1997 hasil tangkapan nelayan di perairan muara Sungai Musi mencapai sekitar 2,750 ton atau sekitar $55 \mathrm{~kg} / \mathrm{ha}$ (Dinas Perikanan Sumsel, 1998). Mengingat potensi produksi ikan dari perairan di lahan persawahan pasang surut di muara Sungai Musi berkisar antara $280-350 \mathrm{~kg} / \mathrm{ha} / \mathrm{th}$, maka tingkat pemanfaatan (TP) sumber daya ikan di perairan tersebut mencapai sekitar 16\%-20\%. Tingkat pernanfaatan yang lebih besar dari potensi alaminya ini dapat terjadi karena adanya jenis-jenis ikan dan udang yang melakukan ruaya dari hulu ke muara sungai dan sebaliknya

Upaya pengelolaan sumber daya perikanan di perairan muara Sungai Musi (daerah rawa pasang surut) sampai saat ini masih belum banyak dilakukan. Peraturan penangkapan yang meliputi pembatasan ukuran mata jaring, bahan peledak, dan bahan racun memang sudah lama diberlakukan di perairan ini. Namun demikian sampai saat ini pelanggaran terhadap peraturan tersebut sering kali terjadi.

Usaha budi daya ikan pernah dilakukan oleh beberapa petani di lokasi persawahan pasang surut Sumatera Selatan. Akan tetapi pada saat ini usaha budi daya ikan tersebut menurun sekali disebabkan sering terjadi kematian massal dari ikan peliharaannya akibat adanya intrusi air laut. Usaha budi daya ikan biasanya dilakukan di kolam pekarangan. Jenis ikan yang dipelihara pada umumnya adalah ikan mas, patin, gurami, dan nila. Ikan yang dipelihara diberi makan pakan buatan (pellet) ala kadarnya. Hasil produksi dari usaha budi daya ini (terutama ikan patin) dijual ke pasar di Palembang. Pembinaan terhadap usaha perikanan budi daya di lahan persawahan pasang surut tersebut jarang sekali dilakukan.

\section{KESIMPULAN}

Berdasarkan hasil dan bahasan yang telah diuraikan di atas, maka dapat ditarik kesimpulan sebagai berikut:

1. Pada umumnya $\mathrm{pH}$ perairan sungai (Sungai Musi, Sungai Sebalik, dan Sungai Lalan) sedikit lebih tinggi dari $\mathrm{pH}$ di saluran irigasi yang cukup rendah (4-5). $\mathrm{pH}$ air kolam umumnya lebih tinggi daripada $\mathrm{pH}$ saluran irigasi. Produktivitas primer perairan berkisar antara $16,2-38,0 \mathrm{mgC} / \mathrm{m}^{2} / \mathrm{jam}$;

2. Densitas plankton yang terdapat di perairan umum di sekitar muara S. Musi dan saluran irigasi sawah, pasang surutnya berkisar antara 24-49 individu/L;

3. Potensi produksi ikan dari perairan yang diteliti berkisar antara $47-350 \mathrm{~kg} / \mathrm{ha} / \mathrm{th}$. Tingkat pemanfaatan sumber daya ikan di perairan muara Sungai Musi baru mencapai sekitar 16\%-20\%;

4. Tumbuhan air di perairan yang diteliti didominasi oleh rumput-rumputan dan ganggeng;

5. Komposisi jenis ikan di perairan Sungai Sebalik, Sungai Lalan, Saluran Irigasi Sekunder (SIS), dan muara Sungai Musi didominasi oleh jenis ikan nonpredator. Pertumbuhan ikan pada umumnya bersifat allometrik dengan nilai faktor kondisi antara 0,753,24 ,

6. Densitas nisbi (CPUE-jumlah) dari komunitas ikan di perairan muara Sungai Musi, Sebalik, Lalan, dan Saluran Irigasi Sekunder (SIS) dalam bulan Juli 1998, September 1998, dan Januari 1999 tidak berbeda nyata satu sama lainnya $(P>0,05)$,

7.Densitas nisbi (CPUE-bobot) dari komunitas ikan di perairan muara Sungai Musi, Sebalik, Lalan, dan Saluran Irigasi Sekunder (SIS) dalam bulan Juli 1998 lebih besar daripada bulan Januari $1999(P<0,05)$, sedang densitasnya antara Juli 1998 dengan 
September 1998, dan antara September 1998 dengan Januari 1999 tidak berbeda nyata satu sama lainnya $(P>0,05)$.

8. Usaha budi daya ikan di kolam pekarangan pernah dicoba dilakukan oleh beberapa petani setempat, namun pada saat ini usaha tersebut hampir terhenti.

\section{SARAN}

Mengingat masih sedikitnya pengetahuan mengenai sumber daya ikan di lahan rawa banjiran (pasang surut) di muara Sungai Musi, maka disarankan untuk lebih meningkatkan kegiatan penelitian sumber daya ikan di lahan tersebut yang hasilnya nanti akan dapat dipakai sebagai bahan untuk merakit alternatif pengelolaan sumber daya ikannya. Kegiatan penelitian sebaiknya lebih ditekankan pada penelitian mengenai dinamika populasi ikan serta usaha penangkapannya.

Oleh karena penguasaan IPTEK budi daya ikan di lahan persawahan pasang surut masih sangat terbatas, maka dalam rangka usaha pengembangan perikanan budi daya di lahan sawah pasang surut Sumatera Selatan perlu dilakukan kegiatan penelitian yang intensif dan terarah dalam bidang budi daya ikan, terutama kegiatan penelitian di bidang domestikasi ikan lokal dan teknologi perkolamannya (pond engineering). Nampaknya jenis ikan nila, gurami, betutu, dan patin merupakan jenis ikan peliharaan yang cukup memberikan harapan.

\section{DAFTAR PUSTAKA}

Almazan, G. and C.E. Boyd, 1978. Plankton Production and Tilapia Yield in Ponds. Aquaculture 15:75-77.

Bloomfield, C. and J.K. Coulter. 1973. Genesis and Management of Acid Sulfate Soils. Adv. Agr. 25:265-326.

Boyd, C.E. 1990. Water Quality in Ponds for Aquaculture. Auburn University. Birmingham Publishing Co., Birmingham, USA. $482 \mathrm{pp}$.

Cole, G. A., 1988. Textbook of Limnology. Third Edition. Waveland Press, Inc. Prospect Heights. 401pp.

Cox, G.W. 1976. Laboratory Manual of General Ecology. Third Edition, W.M. C. Brown Publication Co. Dubuque, lowa. $232 \mathrm{pp}$.

Dinas Perikanan Propinsi Sumatera Selatan. 1998. Laporan Tahunan Dinas Perikanan Tk.I. Sumatera Selatan Tahun 1997. 35 pp.

Djajadiredja, R., A.S. Sarnita, dan F. Cholik. 1982. Program penelitian perikanan perairan umum. Prosiding Seminar Perikanan Perairan Umum. Jakarta, 19-21
Agustus 1981. Pusat Penelitian dan Pengembangan Perikanan, Departemen Pertanian. pp. 309-315.

Gaviria, J.I.M., H.R. Schmittou, and J.H. Groover, 1986. Acid Sulfate Soils Identification, Formation and Implication for Aquaculture. J. Aqua., 1: 94-109.

Golterman, H.L. and R. S. Clymo, 1970. Methods for Chemical Analysis of Fresh Waters. Bell and Bain Ltd., Glasgow. $165 \mathrm{pp}$.

Husnah, A. K. Gaffar dan A.S. Sarnita. 1992. Pendayagunaan lahan rawa untuk budidaya ikan. Prosiding Seminar Hasil Penelitian Perikanan Air Tawar 1991-1992. Balitkanwar, p. 295-300.

Lin, C.K. 1986. Acidification and reclamation of acid sulfate fish pond in Thailand. In J.L. Maclean, L.B. Dizon and L.V. Hosillos (Eds.): The First Asian Fisheries Forum. Asian Fish. Soc., Manila. p.71-74.

Nielsen, L.A. and D.L. Johnson. 1985. Fisheries Techniques. American Fisheries Society, Bethesda, Maryland. $468 \mathrm{pp}$.

Ondara, 1982. Beberapa catatan tentang perairan tawar dan fauna ikannya di Indonesia. Prosiding Seminar Perikanan Perairan Umum. Jakarta, 19-21 Agustus 1981. Pusat Penelitian dan Pengembangan Perikanan, Departemen Pertanian. p.13-32.

Petersen, R.G., 1985. Design and Analysis of Experiments. Marcel Dekker, Inc. N.Y. and Basel. 429 pp.

Purnomo, A. and V.P. Singh. 1982. Problems, field identification and practical solution of acid sulfate soils for brackish water fish pond. South China Sea Fisheries Development and Coordinating Program, Manila. p.49-59.

Purnomo, K., D. W. H. Tjahjo, H. Satria, Ch. Umar, dan A. S. Sarnita. 1992. Penelitian potensi sumber daya perairan Danau Semayang, Melintang, dan Jempang di Kalimantan Timur. Prosiding Seminar Hasil Penelitian Perikanan Air Tawar 1991-1992. Balitkanwar. p.274-284.

Ricker, W.E. 1987. Computation and interpretation of biological statistics of fish populations. Canadian Bulletins of Fisheries and Aquatic Sciences. Bulletin 191. Department of Fisheries and Oceans. Ottawa, Ontario, Canada. $382 \mathrm{pp}$.

SAS Institute Inc. 1985. SAS/STAT Guide for Personal Computer. Version 6 Ed., Cary, N.C. 378 pp.

Utomo, A.Dj., Z. Nasution, dan S. Adjie. 1993. Kondisi ekologis dan potensi sumber daya perikanan sungai dan rawa di Sumatera Selatan. Prosiding Temu Karya llmiah Perikanan Peraiaran Umum: Pengkajian Potensi dan Prospek Pengembangan Perairan Umum Sumatera Bagian Selatan. Palembang 12-13 Februari 1992. Pusat Penelitian dan Pengembangan Perikanan. p.37-61.

Welcome, R.L., 1983. River basins. FAO Fisheries Technical Paper (202). 60 pp. 
Lampiran 1. Jenis ikan yang dapat ditemukan di perairan umum sekitar lahan persawahan pasang surut Sumatera Selatan dalam Juli 1998 - Januari 1999

Annex 1. Fish species found in open waters surrounding the tidal paddy-fields of South Sumatra in July 1998 - January 1999

\begin{tabular}{|c|c|c|c|c|c|c|}
\hline Nama jenis (Species) & $\begin{array}{l}\text { Nama daerah } \\
\text { Local name }\end{array}$ & $\begin{array}{l}\text { Kebiasaan makan } \\
\text { Feeding habit ** }\end{array}$ & $\begin{array}{c}\text { Sungai } \\
\text { (river) } \\
\text { Musi }\end{array}$ & $\begin{array}{l}\text { Sungai } \\
\text { (river) } \\
\text { Sebalik }\end{array}$ & $\begin{array}{l}\text { Sungai } \\
\text { (river) } \\
\text { Lalan }\end{array}$ & $\begin{array}{l}\text { SISI } \\
\text { SIT }\end{array}$ \\
\hline \multicolumn{7}{|l|}{ A. Nonpredator : } \\
\hline Anabas testiduneus & Pepuyu & Omnivora & $v$ & v & v & v \\
\hline Cryptopterus lais & Lais & Karnivora (Carnivora) & v & $v$ & v & - \\
\hline Cryptopterus apogon & Lais bamban & Karnivora (Carnivora) & $v$ & - & - & - \\
\hline Cryptopterus limpok & Lais limpok & Karnivora (Carnivora) & $v$ & v & $v$ & - \\
\hline Cryptopterus cryptopterus & Lais bulu & Karnivora (Camivora) & - & $v$ & - & - \\
\hline Cryptopterus minor & Lais kaca & Karnivora (Carnivora) & v) & - & - & - \\
\hline Cyprinus carpio & Ikan mas & Omnivora & v & - & $v$ & v \\
\hline Dangila ocellata & Siburuk & Omnivora & - & - & $v$ & - \\
\hline Helostoma temmincki & Biawan & $\begin{array}{l}\text { Pemakan plankton } \\
\text { (Plankton feeder) }\end{array}$ & v & v & $\mathrm{v}$ & $v$ \\
\hline Hemirhampodon sp. & Julung-julung & Insektivor (Insectivore) & v & - & $v$ & $v$ \\
\hline Labeobarbus ocellatus & Biis & Omnivora & - & $v$ & - & - \\
\hline Labeobarbus fasciatus & Mangsan & Omnivora & v & v & - & - \\
\hline Leptobarbus hoeveni & Jelawat & Omnivora & $v$ & $v$ & $v$ & - \\
\hline Macrognathus maculates & Silisili & Insektivor (Insectivore) & $v$ & - & $v$ & - \\
\hline Mastacembelus erythrotaenia & Tilan & Ins ektivor (Insectivore) & $v$ & v & - & - \\
\hline Notopterus spp. & Belida & Insektivor (Insectivore) & $v$ & v & $v$ & v \\
\hline Oreochromis niloticus & Nila & Omnivora & v & - & - & - \\
\hline Osphronemus gouramy & Kalui/gorami & Herbivora & v & v & - & - \\
\hline Osteochilus hasselti & Puyau masau & $\begin{array}{l}\text { Pemakan plankton } \\
\text { (Plankton feeder) }\end{array}$ & $v$ & $v$ & $v$ & - \\
\hline Osteochilus kelabau & Kelabau & $\begin{array}{l}\text { Pemakan plankton } \\
\text { (Plankton feeder) }\end{array}$ & - & v & v & v \\
\hline Osteochilus triporos & Puyau & $\begin{array}{l}\text { Pemakan plankton } \\
\text { (Plankton feeder) }\end{array}$ & - & - & - & $v$ \\
\hline Pangasius djambal & Patin & Karnivora (Carnivora) & $v$ & v & v & - \\
\hline Puntius schwanwfeldi & Lampam & Herbivora & v & v & v & $\mathbf{v}$ \\
\hline Puntioplites bulu & Tengadak & Herbivora & v & - & - & - \\
\hline Rasbora cephalotaenia & Seluang & Omnivora & v & v & v & $v$ \\
\hline Trichogaster pectoralis & Sepat siam & Omnivora & v & v & - & $v$ \\
\hline Trichogasterleeri & Sepat & Omnivora & v & $v$ & $v$ & $v$ \\
\hline $\begin{array}{l}\text { Macrobrachium rosenbergii } \\
\text { B. Predator: }\end{array}$ & Udang galah & Omnivora & v) & v) & v) & v) \\
\hline Channa pleuropthalmus & Haruan & Predator & v & $v$ & $v$ & $v$ \\
\hline Channa micropeltes & Toman & Predator & $v$ & $v$ & $v$ & - \\
\hline Mystus nemurus & Baung & Predator & $v$ & v & v & - \\
\hline Mystus sp. & Baung & Predator & v & $v$ & v & v \\
\hline Mystus singgaringan & Senggaringan & Predator & $v$ & - & - & $v$ \\
\hline Oxyeleotris marmorata & Betutu/Bakut & Predator & - & - & - & v) \\
\hline Wallago leeri & Tapah & Predator & v & - & - & - \\
\hline
\end{tabular}

Catatan/Note:

SIS = Saluran Irigasi Sekunder/Secondary Imigation Canal, SIT = Saluran Irigasi Tersier/Tertiary Imigation Canal $\mathrm{v}=\mathrm{ada} /$ present, $\quad$ - = tidak ada/absent, $\mathrm{v}$ ) = Keterangan nelayan setempat/According to local fishermen

** Sumber: Saanin, H\& M. Sachlan, komunikasi pribadi (Source : Saanin, H. \&M. Sachlan, personal communication) 
Lampiran 2. Hasil tangkapan ikan dari percobaan penangkapan dengan jaring insang Annex 2. Catch of experimental gill-netting

\begin{tabular}{lcccccc}
\hline $\begin{array}{c}\text { Bulan-tahun } \\
\text { Month-year }\end{array}$ & Juli (July) 1998 & \multicolumn{2}{c}{ September 1998 } & \multicolumn{2}{c}{ Januari (January) 1999 } \\
\hline \multicolumn{1}{c}{$\begin{array}{c}\text { Stasiun } \\
\text { Station }\end{array}$} & $\begin{array}{c}\text { Jumlah } \\
\text { (ekor) } \\
\text { Number } \\
\text { (individuals) }\end{array}$ & $\begin{array}{c}\text { Bobot (g) } \\
\text { Weight (g) }\end{array}$ & $\begin{array}{c}\text { Jumlah (ekor) } \\
\text { Number } \\
\text { (individuals) }\end{array}$ & $\begin{array}{c}\text { Bobot (g) } \\
\text { Weight (g) }\end{array}$ & $\begin{array}{c}\text { Jumlah } \\
\text { (ekor) } \\
\text { Number } \\
\text { (individuals) }\end{array}$ & $\begin{array}{c}\text { Bobot (g) } \\
\text { Weight (g) }\end{array}$ \\
Sungai (River) Musi & 24.24 & 2187.5 & 8.0 & 820.0 & 7.50 & 653.2 \\
Sungai (River) Sebalik & 11.67 & 1410.5 & 8.25 & 743.0 & 6.75 & 429.9 \\
Sungai (River) Lalan & 10.84 & 1285.6 & 7.50 & 710.5 & 8.25 & 460.7 \\
S.I.S. & 6.75 & 396.4 & 5.84 & 519.5 & 5.75 & 238.4 \\
Rataan (Mean) & 13.36 & 1319.9 & 7.40 & 698.3 & 7.06 & 445.6 \\
\hline
\end{tabular}

Catatan/Note:

SIS = Saluran Irigasi Sekunder/Secondary Irrigation Canal 